\title{
3. The diminutive suffix -dool in placenames of central north NSW ${ }^{1}$
}

\author{
David Nash \\ The Australian National University and Australian Institute of \\ Aboriginal and Torres Strait Islander Studies
}

\section{Introduction}

Almost all the official Australian placenames ending in dool (as officially spelled) are in a region in central northern New South Wales (NSW) and adjacent Queensland; such as Angledool and over a dozen others. In the Riverina district of south-western NSW, in a separate language area, are about eight such toponyms, such as Moombooldool. This intriguing clustering invites investigation.

\section{Method}

The investigation was based on the 81,624 entries in the Geographical Names Register (GNR) of NSW (Geographical Names Board 2011). I also consulted the 36,165 entries in the Victorian placenames database, the Queensland register, and the Gazetteer of Australia (Geoscience Australia 2008). ${ }^{2}$ The process would not have been feasible were these registers not available in bulk in digital form.

The NSW names were sorted from the end of the word, thereby grouping spellings ending in dool, and the few in dule, and one in joole. No other terminations were found which would rhyme with ool according to English spelling. The names were combined into a spreadsheet along with attributes of location and feature type and then were grouped into 'toponymic sets': placenames which involve

\footnotetext{
1 An earlier version of this study was presented on 1 October 2005 as 'Little names: -dool in northern NSW' $^{\prime}$ at the Australian Placenames of Indigenous Origin conference, hosted by the Australian National Placenames Survey at Geosciences Australia, Canberra, and I am grateful to the participants for comments, and subsequently to John Giacon and Maïa Ponsonnet, and Ray Wood. My interest in the topic was originally piqued in a conversation with Jack Waterford and the late Murray Chapman who unintentionally alerted me to the existence of Mercadool homestead in the Walgett district, which I then realised had to be the source for the same placename I had long known in the Parkes district.

2 These and similar resources are conveniently linked from http://www.anps.org.au/resources.html maintained by Placenames Australia (Inc).
} 
the same base name (in the same spelling) in the one locality. For example, in the Walgett LGA (Local Government Area) the Register has four placenames which I group into a single Yarraldool toponymic set:

Yarraldool parish

Yarraldool Bore bore

Yarraldool Ridge ridge

Yarraldool Sand Ridge ridge

Typically the places in such a set are differentiatied by feature type, and/or by various derivations of the base name. Further to this illustration, note that the Gazetteer of Australia (Geoscience Australia 2008) has two other placenames: both are of NSW homesteads in other localities, and so I do not add these into the above toponymic set:

Yarraldool $30^{\circ} 00^{\prime} \mathrm{S} 152^{\circ} 01^{\prime} \mathrm{E}$

Yarraldool $29^{\circ} 08^{\prime} \mathrm{S} 150^{\circ} 29^{\prime} \mathrm{E}$

This process arrived at a collection of basic placenames (and localities thereby named) which terminate in dool (or dule, joole). Along with the coordinates these placenames were transferred (via CSV format and GPSBabel+ software) to a KML file, and thereby displayed in Google Maps and QGIS.

\section{Northern inland NSW}

As can be seen in Map 1, the most notable cluster of placenames terminating in dool (or dule) is in central northern NSW and adjacent Queensland. The 50 or so placenames with this termination can be viewed on Map 1. The placenames in the northern cluster are gathered in Tables 1 and 2 along with information relevant to their etymology.

First we consider in Table 1 those-dool placenames for which we have an etymology based on older records ('testimony') and wordlist data, the placenames for which we can have 'greatest certainty about the meaning of a placename' (Koch 2009: 147-148). For the ten or so placenames in Table 1 there is an old source ${ }^{3}$ which identifies the stem, and all these also involve -dool (or -dule) as a suffix. The suffix is readily identifiable in languages indigenous to the district, notably the closely related Yuwaalaraay and Yuwaalayaay (the name written Euahlayi by Mrs Langloh Parker 1905). This suffix attaches to nominals, is written-dhuul or -djuul

\footnotetext{
3 Notably Royal Anthropological Society of Australia (RASA) (2004) which comprises manuscript questionnaires on placenames returned in about 1899 from local Police and other officials.
} 
in the orthography adopted for the language (or in the cover form -DHuul as in the GYY Dictionary) and carries a diminutive meaning, usually glossed '1. little, small (YR,YY,GR); 2. one (YR,YY)’ (Williams 1980; Ash et al. 2003: 68). ${ }^{4}$

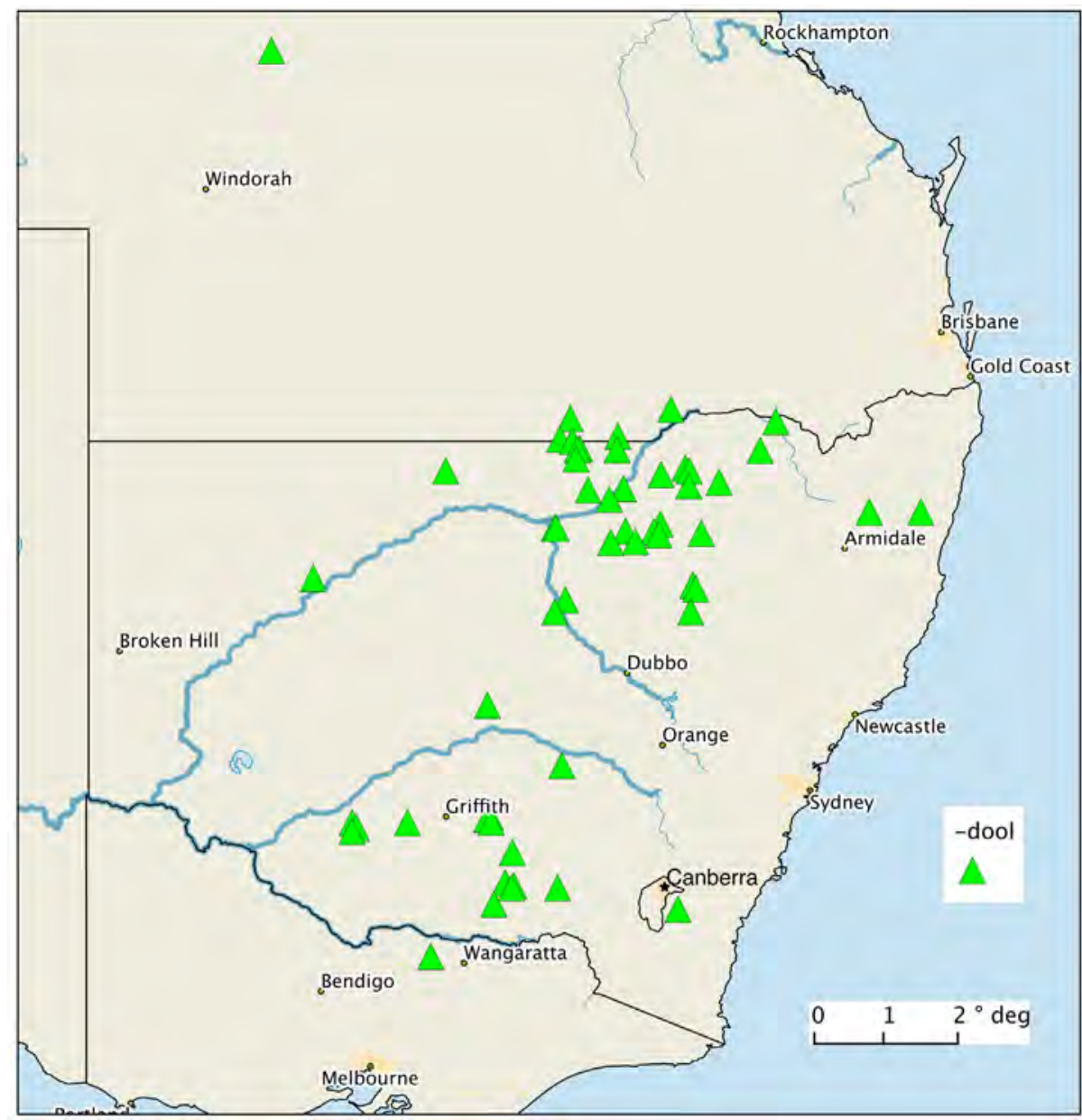

Map 1: Location of toponymic sets of placenames terminating in dool (or dule, joole) marked with green triangle.

Source: Made with QGIS and Natural Earth, free vector and raster map data from naturalearthdata.com.

Then in Table 2 are the remaining -dool placenames in the cluster in the same area, together with whatever stems in the GYY Dictionary can be matched with the form of the placename. The placenames in Table 2, however, lack

4 The abbreviation GYY is sometimes used to name the language comprising the closely related Gamilaraay (GR), Yuwaalaraay (YR) and Yuwaalayaay (YY) languages (Ash et al. 2003: 259). 
supporting testimony from older sources. Note that the distribution of the -dool placename cluster approximates the territory of Yuwaalayaay (YY) and Yuwaalaraay (YR) as shown on the GYY Dictionary map (Ash et al. 2003: 2), and extending into the adjacent Gamilaraay area but noticeably absent from most of the eastern part of the Gamilaraay (GR) area (towards Inverell and Tamworth). I am not aware of what the reasons might be for this absence.

Next, consider the placenames on Map 1 located away from the focal cluster. First, the northernmost placename, the homestead Angledool in central Queensland has the hallmarks of being a transplanted copy name: it is a homestead rather than a natural or indigenous feature (or 19th century administrative area), and is spelled the same as the regionally well-known NSW village inside the focal cluster.

Some of the other outliers are most likely transplants. One such is the homestead name Mercadool west of Parkes: it is not recorded before 1900 (in a newspaper item), and has the same spelling as a well known 19th century pastoral property in northern NSW (see above) and of a racehorse of the period. Nor can the word be matched with a known word in the local Wiradjuri language. Another central NSW placename which may have been transplanted from the GYY area is that of the homesteads Eulendool and Eulandool, ${ }^{5}$ as there is a Eulan parish in the Walgett LGA. ${ }^{6}$

I take the name of Bardool parish in north-eastern NSW (the easternmost location on Map 1) to be a chance resemblance of the final syllable of a disyllabic word: it is an isolated occurrence in a rather different language area. Similarly for the only other dool placename in other states: Coondool Pool (Western Australia).

\section{Southern inland NSW}

As can be further seen on Map 1, the Riverina district in southern inland NSW has virtually the only other placenames in Australia with the dool ending. The information on these is gathered in Table 3. About half have some fragmentary origin information. Little of the origin information can be matched with wordlist entries for Wiradjuri, the relevant language.

5 This name occurs on a homestead north-west of Condobolin, and also on a locality south of Dubbo not in the Geographical Names Register (Geographical Names Board 2011) nor the Gazetteer of Australia (Geoscience Australia 2008). Both of these locations are some distance south of the GYY area. However a possible Wiradjuri stem is yulun 'blackwattle tree' (Grant and Rudder 2010 from Yoo'loon(y) Richards 1902: 183), equivalent to dhulan (YR,YY)), and the owners of the Eulandool property south of Dubbo were told the name 'meant Wattle Clump' (pers. comm. 19 October 2011).

6 The stem cannot be readily matched with a known GYY stem, but compare yulan 'skin' Science of Man 1897 0227 [GCN] (J. Steele pers. comm.), yulang 'skin' (Curr 3), corresponding to yulay (GYY) 'skin'. The placenames Ulan, and Ulandra (in the Junee area) may also be related, but there is no etymology recorded for these names. 
A few of the placenames in Table 3 might have been copied from an original place the northern NSW cluster, notably the homesteads Burrandool and Yarraldool.

\section{A chance syllable?}

While seeking etymologies for the placenames in Tables 2 and 3, we need to allow for the possibility that final dool is just a syllable which chances to match the suffix morpheme -DHuul. To assess this we can consider the wider set of placenames, those which end in ool, and see what proportion of these are specifically dool.

Following the same method as described above, the NSW placenames were sorted from the end of the word, thereby grouping spellings ending in ool, and the few in ule. No other terminations were found which would rhyme with ool according to English spelling. All the names in ool and ule were combined into a spreadsheet along with attributes of location and feature type. Next, names that clearly involve English words were then excluded (e.g. names with Wool, Pool or School). Also the dozen or so placenames in north central NSW involving the topographic term Warrambool (Nash 2011) and similarly the dozen or so names with the term Wakool in the western Riverina, were set aside.

The locations of the remaining toponymic sets are displayed in Map 2. It is apparent on Map 2 that the green triangle dool markers are in the minority except in the north central NSW cluster (where they dominate). Note particularly that in the Riverina there are many more ool placenames than just the dool names, and so (in the absence of other evidence) the chances are higher there that a final dool is just a syllable not a morpheme and not a suffix in its own right. I conclude from the distribution shown in Map 2 that dool names predominate just where they are likely to involve the GYY suffix -DHuul, and elsewhere the placenames are likely to end in a meaningless syllable (i.e. not a morpheme) written dool (or else are a transplanted copy of a genuine -dool name from the GYY area). 


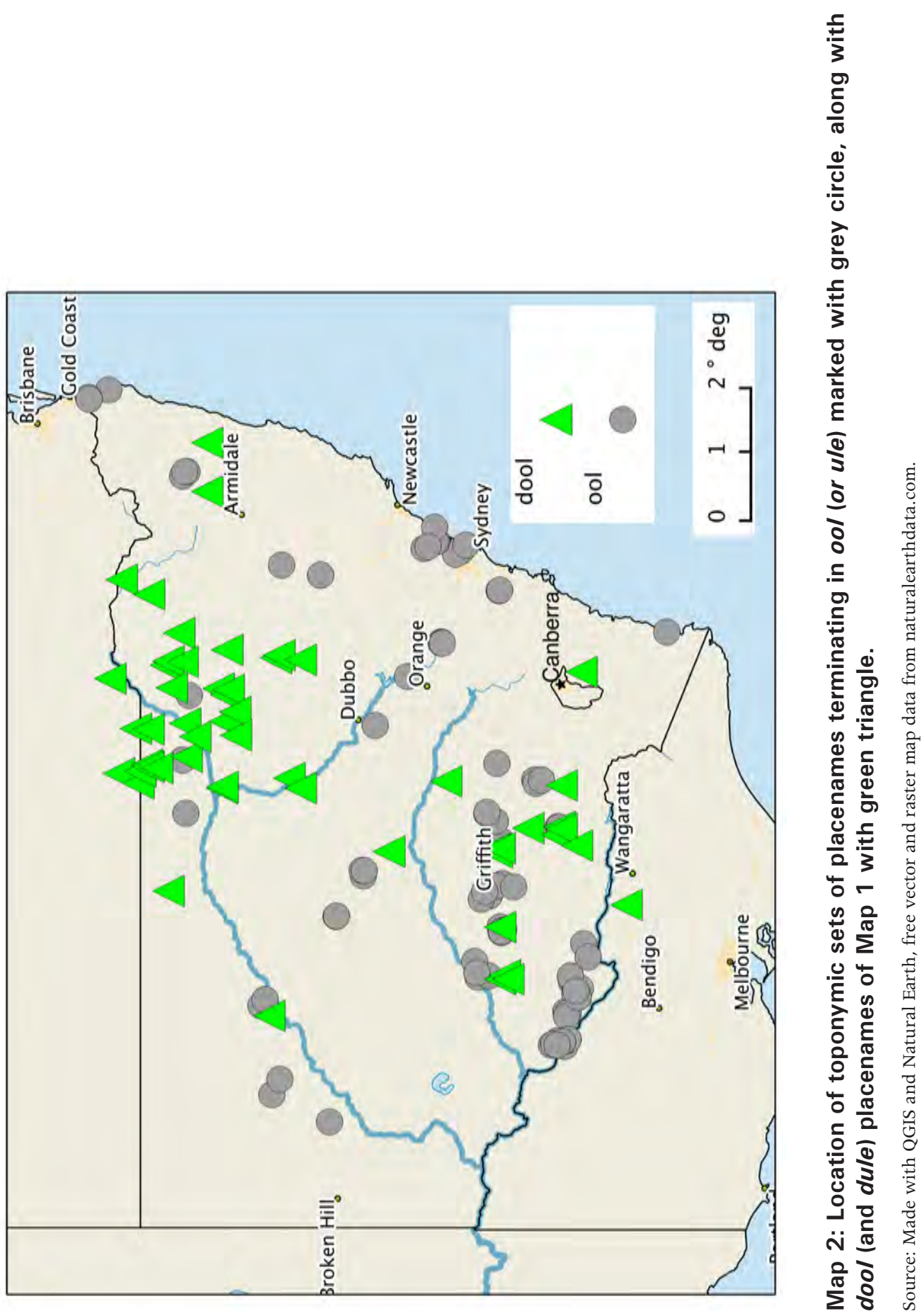




\section{Semantic patterns}

\subsection{Stem types}

Returning to the GYY placenames of northern inland NSW considered above, we can add some semantic considerations to help the assessment of the fragmentary etymological information. For the placenames with relatively secure etymology, in Table 1, we can see that the stem meanings are mostly concrete entities: two flora terms ('reeds' and 'swamp oak'), and two physical features ('cracks', 'stone') along possibly with 'rockhole' (as proposed in the note to Mildool above as an extended sense of 'eye'). The two non-concrete stems are attributes 'small' and 'blind, blunt', though possibly both denoting humans (or animals) ('child' and 'blind person').

These semantic ranges fit fairly well with the speculative etymologies indicated in Table 2: the possible GYY stems listed in Table 2 include flora terms (and also animals), a physical feature ('steep bank'), and human attributes.

\subsection{Semantics of the 'Diminutive'}

The GYY Dictionary glosses -DHuul as '1. little, small; 2 . one' with the comment 'This suffix is attached to nouns, it has a wide range of meanings.'

The second sense is apparent where the suffix occurs in some GYY lexemes, such as Gamilaraay dhiidjuul 'piece of meat' from dhii 'meat' and Gamilaraay gaaydjuul 'small-little, just, one' based on gaay '1. small, little; 2. child'. ${ }^{7}$ In other words, the so-called diminutive does not always carry the sense of 'little, small', but rather sometimes functions as a definitiser or individuator, related to its hypocoristic function and the formation of proper names. This extended function of the diminutive is not uncommon in languages around the world; see Dressler and Barbaresi's (1994: 116-169) wide-ranging discussion, and Jurafsky (1996: 555-556) on the Individuating or Partitive sense of the diminutive.

It is typical for a diminutive morpheme to have other senses as well as the two noted in the GYY Dictionary. It is common for the diminutive to be used affectively, so that the diminutive of $\mathrm{X}$ expresses an attitude to $\mathrm{X}$, something like 'dear (little) X'. A couple of GYY lexemes possibly involve an affective component: milanduul (Y) 'alone, only one' (milan 'one'), and marayrrdhuul 'childless woman' from marayrr 'no, none', -dhuul 'one'. And in some languages the diminutive of a placename expresses that the place is familiar (Jurafsky 1996: 539 on Cantonese; Simpson 2001).

7 Recently an extra sense has been added for gaaydjuul: 'suffix/prefix' (Giacon 2006: 2), probably drawing on the homophonous stem gaay (YR,YY) '1. word; 2. message; 3. language; 4 . story'. 
From some of the glosses from old sources given in Table 1 we can see that the 'small' sense is not always present in GYY diminutives. For instance, when suffixed to a human attribute stem -DHuul means 'the one who is', possibly also with an affective component, such as gaaynduul 'baby' (Kiandool), and probably mugadhuul 'blind person' (Mookadool and possibly Murkadool). In the neighbouring language to the south-west, Ngiyampaa, '- $D H u l$ is a singular diminutive' and 'the 'littleness' of the diminutive is associated with emotional attachment' (Donaldson 1980: 100-102). ${ }^{8}$

It is thus likely that some of the -dool placenames do not involve the sense 'small' even where it might be plausible. Thus, when the diminutive is combined with a flora term such as 'reeds' or 'swamp oak', the sense could be better translated in English by the definite article; thus Drildool 'The Reeds', Mercadool 'The Oaks', Noongadool 'The Currajongs'. It is natural for a placename (as a proper name) to involve a sense of definiteness, and so it may well be that most -dool placenames are definites and do not involve literally smallness of size.

\subsection{Diminutive placenames}

Diminutives have not been reported in placenames elsewhere in Australia, at least, not in placenames in Australian Indigenous languages.

For Australian English Simpson (2001) has reported hypocoristic versions of Australian placenames, some of which (such as Bundy for Bundaberg) use the Australian English ending spelled $-y$ or $-i e$ which is a diminutive, among other functions. Another strand in Australian English hypocoristic placenames are formations with The, as in The 'Gong (Wollongong) (Simpson 2001). Thus there is a partial parallel in Australian English to my analysis of the -dool placenames in the Yuwaalayaay (and GYY) language.

Another formation which can be seen as another kind of placename diminutive is the pattern of English placenames modified with the adjective 'Little'. A placename Little A typically relates a location to another nearby location bearing the same base name $A$, as for instance the pair of locations Little Hartley and Hartley in the western Blue Mountains, or the Little Sandy Desert and Great Sandy Desert (in Western Australia). A related kind is represented by Little Austria in the Snowy Mountains, where the locality is named to echo a more famous distant locality with some perceived shared property. We could call this type an external diminutive; it is not uncommon in English placenames in Australia, but it is quite unusual (or perhaps nonexistent) in Australian placenames of Indigenous origin. There is no evidence that the external diminutive plays any

8 Note, however, there are no recorded placenames containing - DHul in the associated Wangaaybuwan country, unless one counts the Eulandool property north-west of Condobolin. 
role in the -dool placenames of Yuwaalayaay and Yuwaalaraay. In central NSW there appear to be some external diminutive examples involving Nyrang ${ }^{9}$ such as Boree Nyrang and Eurow Nyrang Mountain, but these placenames likely arose in the context of NSW Pidgin.

In contrast to the external diminutive is what could be termed the internal diminutive, of which some - dool placenames are exemplary. Thus the example above with the clearest known origin, Mildool, is '[[small rockhole] place]' rather than '[small [rockhole place]]'; the other, Yarraldool '[[small stone] place]', is also based on a physical feature stem. As an aside, note that English placenames with internal diminutive are also typically restricted to names derived from a feature type, such as Little Bay or Little River.

\section{Conclusion}

The recorded Australian placenames ending in dool are concentrated in the territory of the closely related Yuwaalayaay and Yuwaalaraay languages of central northern NSW and adjacent Queensland, and exhibit the nominal suffix - DHuul with definite, individuating or diminutive meaning in those languages. While this is an unusual derivation for placenames in Australian languages, there are some parallels in English. Another apparent cluster of dool placenames in the NSW Riverina are of disparate origin, and do not reflect a suffix of the local language there.

9 Nyrang is a spelling of the second of "Aboriginal colloquialisms such as 'cobbon' (big) and 'narrang' (small)" (Wesson 2001: 31), cf. Sydney Language ngarang 'small' Wafer and Lissarrague (2008: 623). 
Indigenous and Minority Placenames

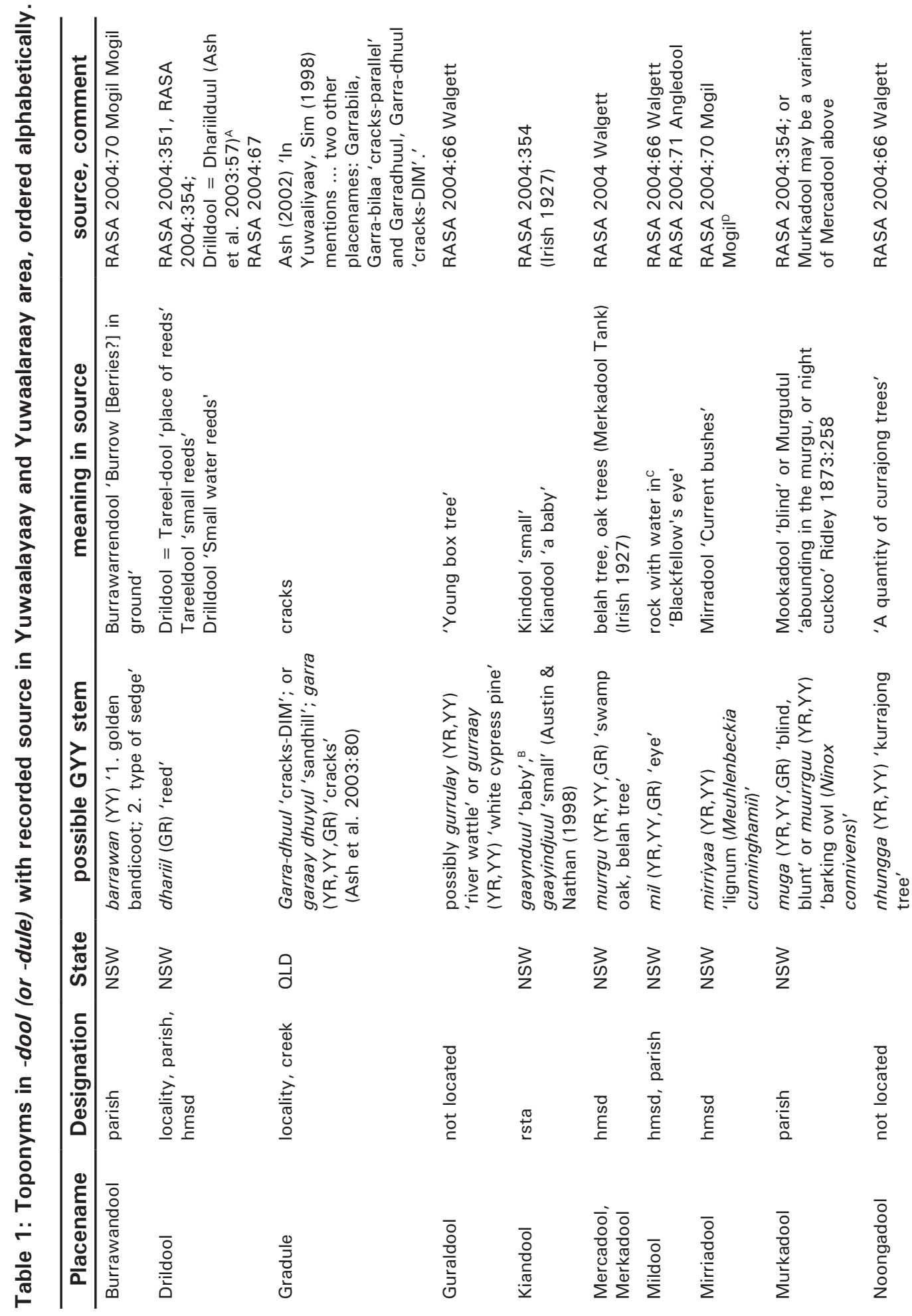


3. The diminutive suffix -dool in placenames of central north NSW

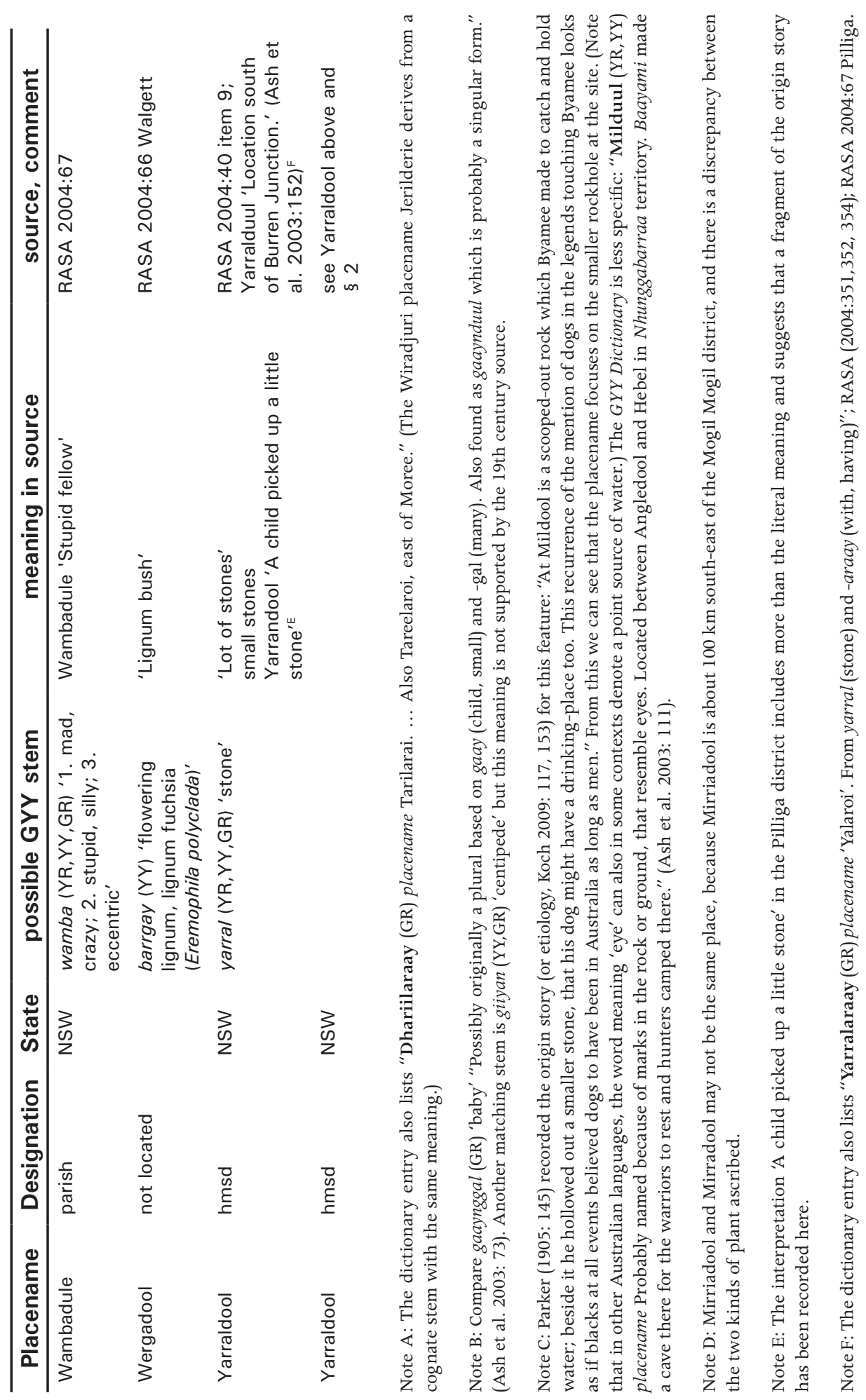


Indigenous and Minority Placenames

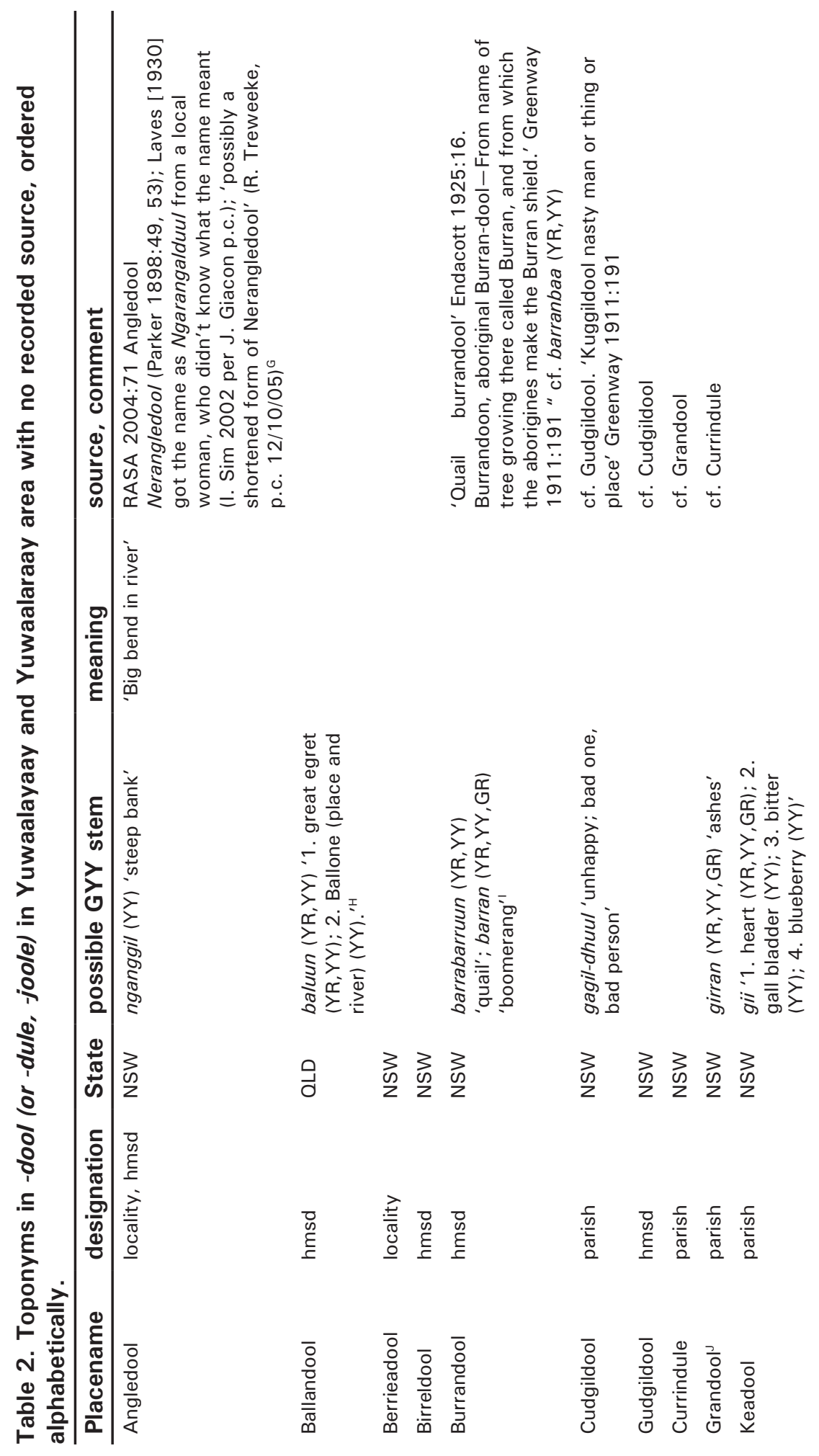


3. The diminutive suffix -dool in placenames of central north NSW

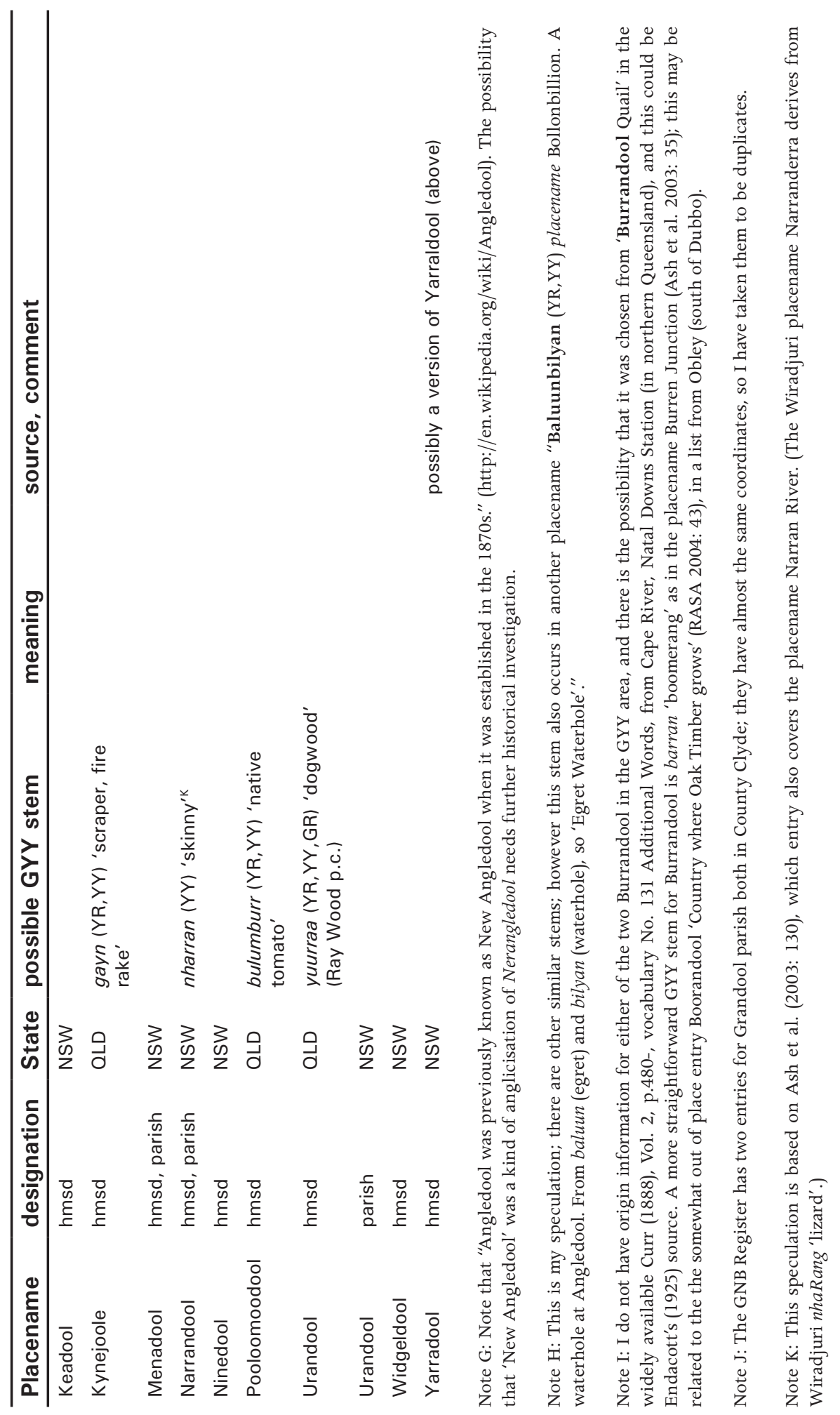



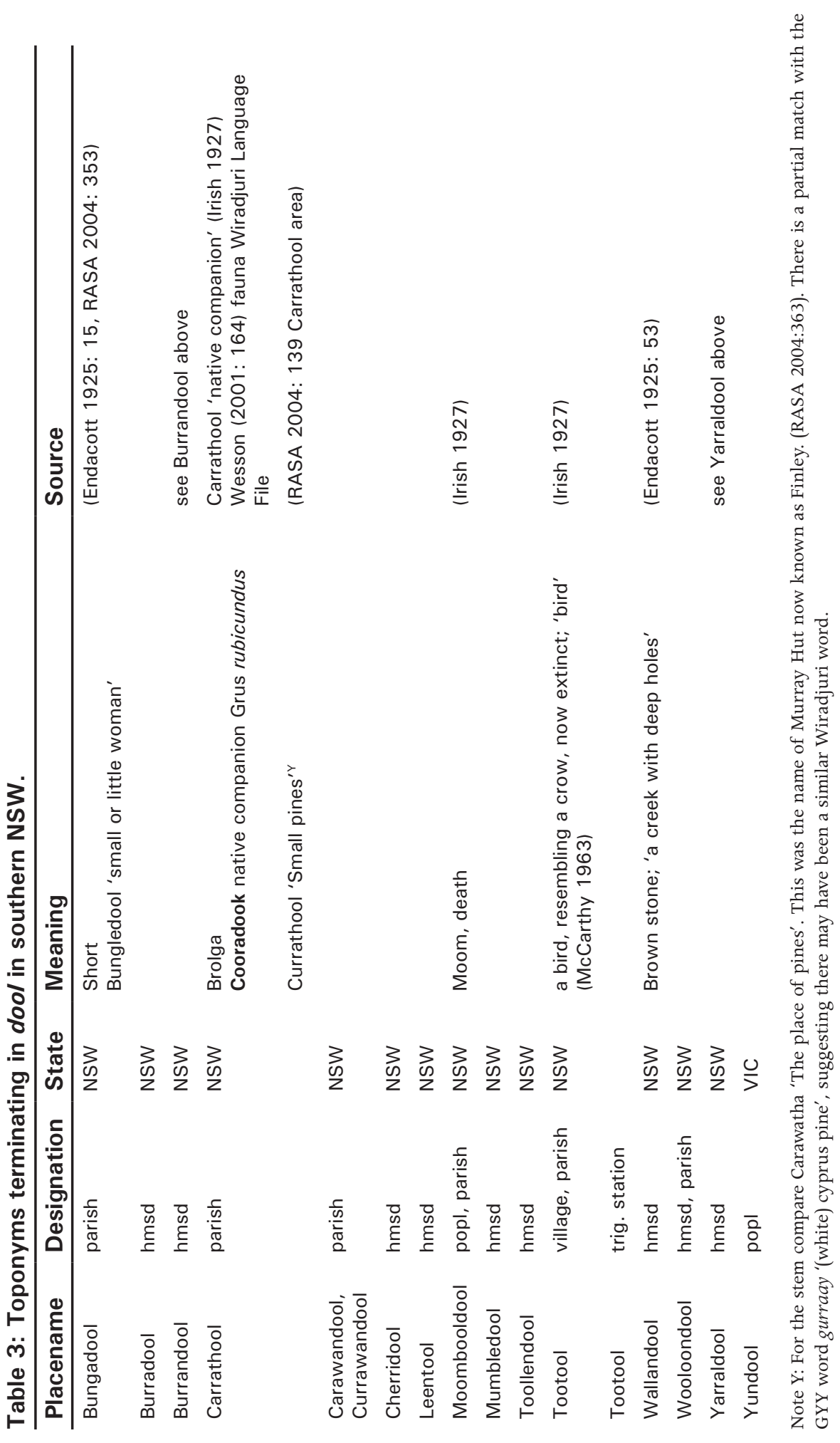

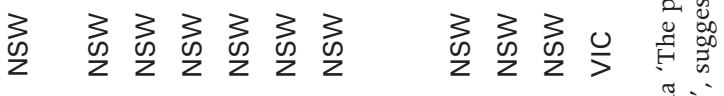

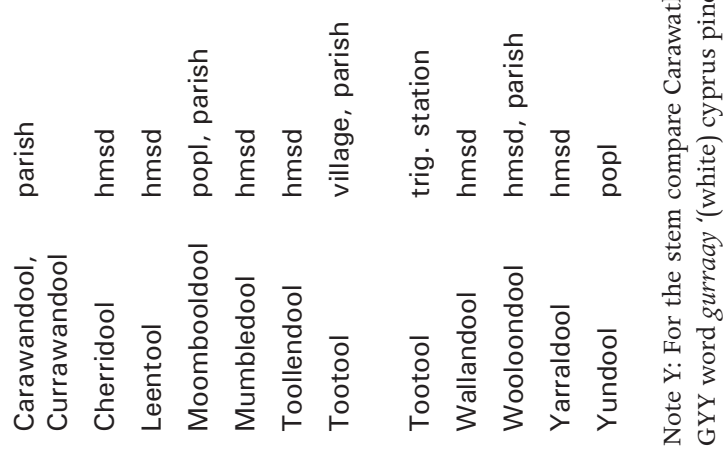




\section{References}

Ash, A. 2002, 'Placenames in Yuwaalaraay, Yuwaalayaay and Gamilaraay of north-west New South Wales', in The Land is a Map: Placenames of Indigenous Origin in Australia, Luise Hercus, Flavia Hodges and Jane Simpson (eds), Pandanus Books for Pacific Linguistics, Canberra: 181-185.

Ash, A., J. Giacon and A. Lissarrague (eds) 2003, Gamilaraay, Yuwaalaraay and Yuwaalayaay dictionary, IAD Press, Alice Springs.

Austin, P. and D. Nathan 1998, Kamilaroi/Gamilaraay Web Dictionary. http:// coombs.anu.edu.au/WWWVLPages/AborigPages/LANG/GAMDICT/ GAMDICT.HTM (accessed 6 May 2012).

Donaldson, T. 1980, Ngiyambaa, the Language of the Wangaaybuwan, Cambridge Studies in Linguistics 29, Cambridge University Press, Cambridge.

Dressler, W. U. and L. M. Barbaresi 1994, Morphopragmatics: Diminutives and Intensifiers in Italian, German, and other Languages, Studies and Monographs 76, Walter de Gruyter, Berlin.

Endacott, S.J. 1925, Australian Aboriginal Native Names, and their Meanings, (2nd edn), Melbourne.

Geographical Names Board 2011, Geographical Names Register (GNR) of NSW, Land and Property Information, New South Wales: http://www.gnb.nsw. gov.au/name_search (accessed 6 May 2012).

Geoscience Australia 2008, Gazetteer of Australia 2008 Release. Searchable at http://www.ga.gov.au/map/names/ (accessed 6 May 2012). See also Gazetteer of Australia 2010 Release.

[Giacon, J.] 2006, Gaay Garay Dhadhin: new words. 3 pp. file. http://www. yuwaalaraay.org/documents/GaayGarayDhadhin.doc (accessed 24 September 2011).

Greenway, C.C. 1911, 'Kamilari tribe', Science of Man 12(10):191, 13(6):125.

Grant, S. and J. Rudder 2010, A New Wiradjuri Dictionary, Restoration House, O'Connor, ACT.

Irish, C.A. 1927, 'Names of railway stations in New South Wales. With their meaning and origin', Royal Australian Historical Society 13: 99-144. http:// www.nswrail.net/library/station_names.php/(accessed 6 May 2012).

Jurafsky, D. 1996, 'Universal tendencies in the semantics of the diminutive', Language 72(3): 533-578. 
Koch, H. 2009, 'The methodology of reconstructing Indigenous placenames: Australian Capital Territory and south-eastern New South Wales', in Aboriginal Placenames: Naming and Re-naming the Australian Landscape, Harold Koch and Luise Hercus (eds), Aboriginal History Monograph 19, ANU E Press and Aboriginal History Incorporated, Canberra: 115-171. http://epress.anu.edu.au?p=17331/ (accessed 6 May 2012).

McCarthy, F. D. 1963, New South Wales Aboriginal Place Names and Euphonious Words, with their Meanings, Australian Museum, Sydney.

Nash, D. 2011, 'What's a Warrambool?', Posted on Endangered Languages \& Cultures blog, 19 June 2011, 11:06 am, http://www.paradisec.org.au/ blog/2011/06/what's-a-warrambool/ (accessed 6 May 2012).

Parker, K. L. 1898, More Australian legendary Tales, D. Nutt, London. http://www. archive.org/details/moreaustralianlo0parkgoog (accessed 6 May 2012).

- 1905, The Euahlayi Tribe. A Study of Aboriginal Life in Australia, Archibald Constable and Company Ltd, London. http://books.google.com.au/ books?id=vWU8Vu7enKwC (accessed 6 May 2012), http://www.gutenberg. org/ebooks/3819 (accessed 6 May 2012).

Richards, C. 1902, 'Wirra' Dthooree — Wirrai' Yarrai'. Wirrach' Aree' Wirra' Jer-ree", Science of Man 5(11): 180-183.

Ridley, W. 1873, 'Australian languages and traditions', Journal of the Anthropological Institute of Great Britain and Ireland, 2: 257-275. http:// www.jstor.org/stable/2841174 (accessed 11 April 2014).

Royal Anthropological Society of Australia (RASA) 2004, Royal Anthropological Society of Australia manuscripts dated 1900, 'Anthropological Society of Aus roll 1', PDF file. CD-ROM, Geographic Names Board of NSW.

Simpson, J. 2001, 'Hypocoristics of place-names in Australian English', in Varieties of English: Australian English, Peter Collins and David Blair (eds), Benjamins, Amsterdam, Philadelphia: 89-112.

Wafer, J. and A. Lissarrague 2008, A Handbook of Aboriginal Languages of New South Wales and the Australian Capital Territory, Muurrbay Aboriginal Language and Culture Co-operative, Nambucca Heads.

Wesson, S. 2001, Aboriginal Flora and Fauna Names of Victoria: As Extracted from Early Surveyors' Reports, Victorian Aboriginal Corporation for Languages, Melbourne. http://www.vaclang.org.au/project-detail.aspx?ID=9 (accessed 6 May 2012) http://www.vaclang.org.au/admin \%5Cfile \%5Ccontent9\%5Cc $7 \% 5$ Cff.pdf. 
3. The diminutive suffix -dool in placenames of central north NSW

Williams, C.J. 1980, A Grammar of Yuwaalaraay, Pacific Linguistics B-74, Pacific Linguistics, ANU, Canberra. 
This text taken from Indigenous and Minority Placenames: Australian and International Perspectives, Edited by Ian D. Clark, Luise Hercus and Laura Kostanski, published 2014 by ANU Press, The Australian National University, Canberra, Australia. 